\title{
Personalized Learning: Empowering a Student with Autism Spectrum Disorder in Basic Grammar Course
}

\author{
Lemmuela Alvita Kurniawati \\ Universitas Kristen Duta Wacana, Yogyakarta, Indonesia \\ Email: pipitkh@staff.ukdw.ac.id
}

\begin{abstract}
This paper provides illustrations of how a personalized learning approach is implemented in the Basic Grammar course to empower a student with an autism spectrum disorder is taking the ownership of learning and meeting his learning needs based on his strengths, weaknesses, and interests. Building upon literature and pedagogical practices of personalized learning, this paper details the innovations implemented in the Basic Grammar course for a student with an autism spectrum disorder to take more control of his learning, facilitate decision-making and communication skills, and engage in the learning process. Additionally, the innovations implemented in this course mirror the essence and principles of personalized learning. This paper is expected to enrich educators in the attempts to adopt a personalized learning approach and to give new insight into how to implement personalized learning in an inclusive classroom. Moreover, it is hoped that the idea of equity in inclusive education by implementing personalized learning could be an omnipresent practice to improve the quality of education for all in Indonesia.
\end{abstract}

Keywords: personalized learning; Basic Grammar Course; Autism Spectrum Disorder.

\section{INTRODUCTION}

As personalized learning has gained its popularity in an inclusive educational setting, its literature and practices have become more refined that there is no single definition across the field of the study (NCLD, n.d.). However, the definitions have been varied across the contexts according to the implementations and settings. Fundamentally, personalized learning creates a learning environment where students with disabilities can determine their pace of learning based on their strengths, weaknesses, interests, and skills. Personalized learning aims to put students as active

participants in their learning process and incorporate some approaches which accommodate the different needs of students, including those with disabilities. Moreover, it promotes the success of learning by creating students learning engagement, providing meaningful assessment, establishing individualized learning plan, and exercising students' problem solving and critical thinking skills (Jenkins and Keefe, 2002; Jones and Casey, 2015; Kim, 2012; Pane et al., 2015).

Basic Grammar course is one of the compulsory courses for first-year 
students in the English Education Department. Attended by students with various backgrounds, different language competence, and learning abilities, this course requires all students to learn the basics of English grammar and apply them in writing assignments. At the end of the course, by applying the grammatical items learned during the semester, all students were assigned to write a short article about themselves or their closest friend/relative and to set up a personal blog for showcasing their writings during the semester. In order to ensure the goal and objectives of the course attained and all students had equal learning opportunities, I implemented personalized learning in this course to accommodate the needs of both regular students and the student with an autism spectrum disorder. Specifically, some innovations derived from personalized learning approaches were implemented to empower the student with an autism spectrum disorder in facilitating his learning. To provide a clear picture of how personalized learning was implemented in Basic Grammar course, this paper provides essential information, such as the description of the course, the student's with autism spectrum disorder profile, the rationale of implementing personalized learning for a student with autism spectrum disorder, and how the personalized learning was implemented through some innovations. In doing so, it is expected that educators, practitioners, and researchers may adopt this approach and modify the activities based on the corresponding contexts to accommodate the needs of both regular students and students with an autism spectrum disorder in promoting their learning.

\section{DISCUSSION}

\subsection{Course Description}

Basic Grammar course discussed in this paper is a compulsory, threecredit course for the first semester students of English Education Department attending the 2018-2019 academic year in Mahasa University Indonesia (pseudonym). The course which was held between August to December 2018 required the students to attend the class once a week, read the course materials before the class, do some quizzes and written assignments, and set up their own blog to showcase their written works. Additionally, in this course, the students learn the basics of English grammar, such as parts of speech, phrases, past, present, and future tenses, subject-verb agreement, and coordinating conjunctions through some activities. Among others, the activities included class discussion, flipped and jigsaw learning, games, material presentations, project-based assignment, and bi-weekly written article assignment. By the end of the course, the students were expected to be able to optimally apply the grammatical items they have learned during the semester into a 500-word essay describing themselves or one of their closest friends.

At the beginning of the lesson, every first day of students learning 
new grammatical item(s), students were divided into some groups, which were known as "expert groups", based on the same segmented materials they had read before the class to discussed the content materials and clarified some questions they had. This activity that was usually done between fifteen to twenty minutes, then by having one student each from "expert groups", students were assigned to the "home groups" sharing and discussing the segmented materials they had in the "expert groups". This activity that was known as jigsaw discussion, was held once every two or three weeks. Following the jigsaw discussion, the lecturer discussed and clarified some questions from the materials. The discussion focused on the grammatical pattern, its function(s), and some contextual examples. Furthermore, students were assigned to do various activities following the lecture, such as doing some practice, play games, do the quiz, do the project-based assignment, and/or write a short paragraph using the grammatical items they had learned previously. Fundamentally, by the end of the class, students were assigned to write a piece of writing by using the grammatical items they had learned previously.

In measuring students' progress and accomplishments in applying their knowledge and understanding of the grammatical items learned during the course in real-life settings, this course applied authentic assessments. The assessments devised in this course consisted of peer assessments, writing assignments, and a blog consisting of their journal writings. Peer assessments conducted at the end of the jigsaw discussion sessions were done by students' friends in the jigsaw discussion group based on students' understanding of the assigned materials. The second assessment, writing assignments, was conducted every meeting to measure students' understanding in applying the grammatical items into context. The last assessment was setting up a blog consisting of all their written works during the semester.

\subsection{Student's Profile}

Nyawiji Pertiwi, a pseudonym, is currently in his second year in the English Education Department, Mahasa University Indonesia and has just accomplished Basic Grammar course in the odd semester of the 2018/2019 academic year. However, his accomplishment in the Basic Grammar course was a combination of his determination, hard work, and collaborative work between Nyawiji and me through a pathway of the personalized learning journey.

As a student with autism, Nyawiji attended a private vocational school majoring in culinary, prior to entering his college years. Although he had always been interested in music, English language, and theology, he decided to pursue his study in a vocational school due to his limited competence, knowledge, communication, social, and interpersonal skills. The school curriculum had been limited in accommodating and providing an 
appropriate education for students with autism, however, his parents had provided him with various opportunities to develop and follow his passion in music, English language, and theology by involving him in many religious activities in their church. Nyawiji's parents and teachers had been very supportive and encouraging and played an important role in motivating Nyawiji to pursue his higher education.

Despite the fact that he successfully accomplished this course with a minimum score, the process to reach this point in his learning journey was not easy for Nyawiji. Nyawiji had taken the Basic Grammar course twice. He joined his first Basic Grammar course when he was in his first semester of the 2017/2018 academic year, and his final grade did not meet the standard required to pass the course. Nyawiji's overall progress during the semester was not satisfying although he attended the class regularly and participated actively in all class activities. He seemed to be overwhelmed with the assignments and homework every meeting. Additionally, interventions and innovations for a student with autism were not made available during his first Basic Grammar course. Nyawiji was given the same assignments without any personalized instructions, modification, substitution, and duplication of each assignment given during the course. As a result, Nyawiji had been more apprehensive about doing the assignments and homework, understanding complex instructions, and applying the grammatical items in various contexts.

However, the following year, between August to December 2018, Nyawiji had decided to retake the Basic Grammar course and with his determination challenged himself to learn more about basic grammar in this course. During this class, some interventions and innovations were made available to accommodate Nyawiji's learning and needs and to increase the opportunities to develop his skills and knowledge at his pace. The innovations for Nyawiji in Basic Grammar course will be elaborated to provide more insights into how the innovations were implemented in class and the class support system in ensuring success.

\subsection{Personalized Learning for a Student with Autism Spectrum Disorder}

Autism or autism spectrum disorder refers to neurodevelopmental disorders affected individuals and impaired their communication skills, social interactions, and behavioral aspects (Conroy, Sticher, and Gage, 2011). Autism spectrum disorder ranges from low to high in its continuum which embodies different levels of intelligence. The higher spectrum of autism, also known as High Functioning Autism, characterizes individuals whose intelligence is between normal to an above-normal level. In addition, the lower spectrum of autism refers to individuals whose intelligence is below the normal range and those whose communication 
skills and abilities are limited. In essence, individuals with autism spectrum disorder mostly have communication impairments ranging from low to high, depending on the continuum, and social related issues.

Some studies (Weiwu and Chen, 2000; Honda et al., 2005; Sun and Allison, 2010) reported that the prevalence of autism spectrum disorder in Asian educational settings is increasing over time. Indonesia, in particular, has an increased number of students with autism spectrum disorder between 2010 to 2016 (Septia et al., 2016). With the increased numbers of students with an autism spectrum disorder, interventions and innovations are needed to accommodate their needs in granting equity in education. Further, Septia et al. (2016) and Setyoputri (n.d.) claim that specific and personalized treatments are the best approaches that are likely to be successful to deal with students with autism spectrum disorder in an educational setting.

Pritchard (2009) asserts that students with autism spectrum disorder will not respond the same ways as other students in the classroom dealing with classroom activities relatedness issues, such as understanding concepts, socializing, and communicating their ideas, thoughts, and feelings. To be able to deal with students with an autism spectrum disorder, Pritchard (2009) advocates some approaches, principles, and strategies which are likely to be successful to provide support and opportunities in learning. In relation to this, The Education and
Training Inspectorate (ETI) of the Department of Education in Northern Ireland (DENI 2016) has published a booklet, 'Autistic Spectrum Disorders: A Guide to Classroom Practice', which provides a complete guideline of how to deal with students with an autism spectrum disorder in classroom settings. Some of the principles derived from this guideline are as follows.

1) Reducing the amount of language in giving instructions. The language used should be clear, simple, and direct.

2) Giving an adequate amount of time to process and understand information rather than expecting immediate answers

3) Avoiding idioms when speaking; students with autism spectrum disorder are more likely to take them literally

4) Working with routines and structures on a daily basis

5) Setting realistic and attainable targets in a short-term period of time

6) Keeping the environments informed of the strategies applied

In addition, personalized learning has gained traction in meeting the needs of students with an autism spectrum disorder. The Institute for Personalized Learning (CCSSO, 2017) defines personalized learning as an approach where teachers and students work collaboratively to tailor learning based on students' strengths, needs, and interests. A personalized learning environment allows students to take 
an active part in setting the goals of the learning, planning their learning, tracking and determining how learning will be conducted. Fundamentally, personalized learning provides opportunities for students to take ownership of learning by including some activities, such as project-based learning assignments, establishing individualized learning plans, establishing performancebased assessments, and creating student portfolios (Childress and Benson, 2014).

A personalized learning environment provides differentiated learning experiences not only for students without disabilities but also for students with disabilities, autism spectrum disorder in particular (Worthen, 2016). Personalized learning allows students with an autism spectrum disorder to be integrated into general education classes without the feeling of being singled out. In addition, this approach tailors the learning paths for students with autism spectrum disorder based on their strengths, weaknesses, learning progress, and performance.

\subsection{How Personalized Learning Works in Basic Grammar Course}

Derived from the theory of personalized learning as the umbrella of the innovations applied in Basic Grammar course, some innovations were done to provide opportunities for the student with an autism spectrum disorder to take ownership of learning and meet their learning needs. The innovations were jigsaw discussion, explicit and systematic instructions through Green Card, performance-based assessment writing, and project-based assignment. The following paragraphs explain and illustrate how each innovation mirror the essence and principles of personalized learning.

\section{Jigsaw Discussion}

Personalized learning allows students with disabilities to be integrated into classroom activities where they can work collaboratively with their peers in an inclusive classroom setting (Worthen, 2016). This strategy provides them great opportunities to communicate, collaborate, and improve their critical thinking and problem-solving skills, and provides support from the learning environments without being stigmatized and singled out. As part of this strategy, jigsaw discussion matches the needs of students with disabilities in involving them actively in the learning process, helping them in expressing their thought, ideas, and aspirations.

Jigsaw's discussion is an innovation done in the Basic Grammar course, and this innovation involved the student with an autism spectrum disorder in discussing the content materials with their peers. In jigsaw discussion, the student with autism spectrum disorder initially worked with his "expert group" to share, discuss, and clarify questions related to the assigned materials he had read before the class. In this group, a student with autism spectrum disorder discovered a 
shared problem solving based on the questions or problems found in the content materials. This innovation enhances students with autism spectrum disorder's learning experience and empowers them in exercising their communication skills and collaborating with their peers to identify the problems and blend the solutions into shared understandings (Friend and Bursuck, 2012).

The activity, then followed by cross-sharing the content materials they have prepared and discussed in the "expert groups". Students were divided into new groups consisting of different members from the "expert groups", and formed a new group named "homegroup". In this "homegroup", students shared their assigned content materials to the other members of the group who had different content materials. This jigsaw discussion benefitted the student with autism disorder as it increased his engagement and achievement, built his decisionmaking skill and confidence, assessed his understanding of the content materials learned, and reduced the stigma of being singled out (NCLD, n.d.). Moreover, in this innovation, a student with autism could assess not only his understanding but also his peer's understanding by grading their peers' performance in explaining the materials. His peers, on the other hand, would be able to assess his performance by using the provided rubric shown in Figure 1.

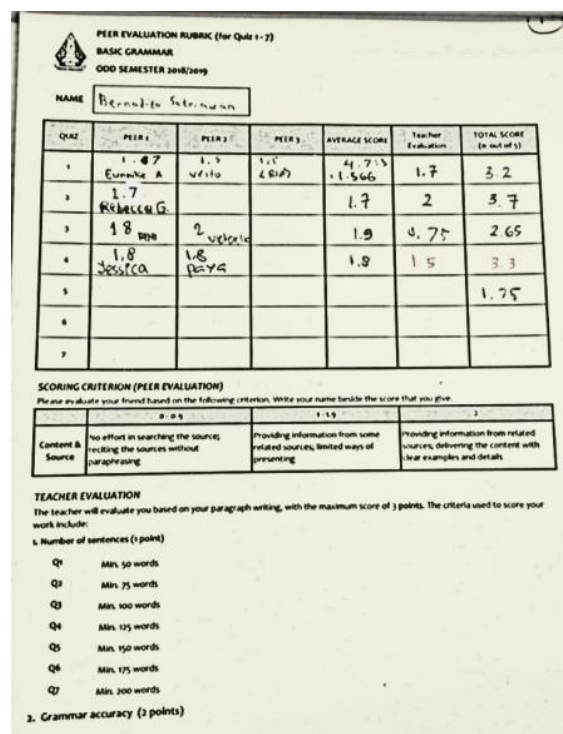

Figure 1. Jigsaw discussion peer evaluation card

\section{Explicit and Systematic Instructions through Green Card}

The second innovation applied under the umbrella of personalized learning is providing explicit, simple, clear, and systematic instructions by using the Green Card. Green Card contained a set of explicit, simple, and clear instructions given systematically for the student with autism spectrum disorder to facilitate him in understanding classroom instructions, as seen in Figure 2. This card is printed in a piece of green A4sized paper and given at the end of each meeting. Green was chosen because the term Green Card resembles the permit for immigrants to stay and work in the United States of America, therefore, it gives hope, encouragement, and motivation for the student with an autism spectrum disorder to craft his learning paths well. The Green Card, furthermore, was given at the end of each meeting to help the student with autism spectrum disorder set his 
patterns and routines during his learning process. As asserted in DENI (2016) that one of the strategies which are likely to be successful to facilitate students with an autism spectrum disorder in their learning is providing them a set of routines and structures on a daily basis.

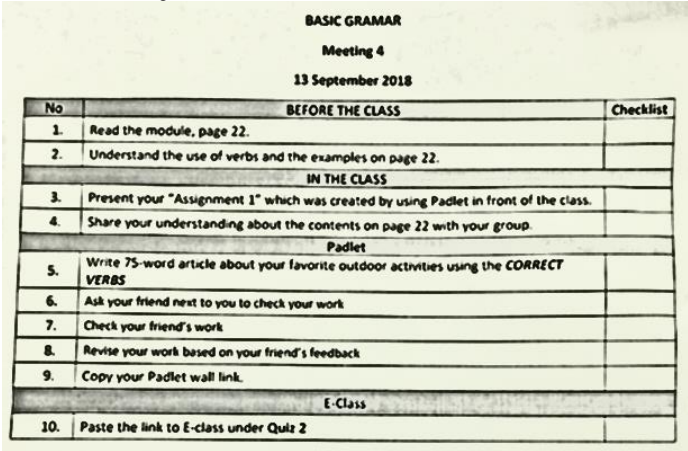

Figure 2. Green Card - Personalized instructions

Green Card seemed to be successful in helping the student with an autism spectrum disorder in the Basic Grammar course. Nyawiji did not experience a high level of apprehension, anxiety, or nervousness in this course. The checklist column provided in the card helped him in reminding instructions he had done inside the class, before the class, or in the online class. Both the systematic instructions and the checklist built his confidence in doing and following the activities. In essence, Green Card innovation is in line with the strategies in dealing with students with disabilities in the classroom as proposed by DENI (2016) and the characteristics of personalized learning as it helped a student with an autism spectrum disorder to set structured activities on a daily basis, and it tailored learning based on the needs of the student.
Performance-Based Assessments

Performance-based assessments, as one of the practices in personalized learning, are defined as the way of assessing students by involving them in tasks that require them to apply and demonstrate their knowledge, skills, and strategies through creating a product (Djoub, 2018). With regard to this, in Basic Grammar course, the students, including the student with autism spectrum disorder were encouraged to apply the grammatical items they have learned each meeting into a short paragraph writing, as illustrated in Figure 3. Before involving the students in the tasks, students were provided with an assessment rubric along with the criteria to grade the tasks (i.e. grammar, number of sentences, spelling, and punctuation, and task accomplishment).

Adjustments were made available for the students with an autism spectrum disorder to accommodate his needs. The students with autism spectrum disorder were asked to include some grammatical items he thought he knew well and the number of sentences he could be able to write. However, although some adjustments were made, the considerations of making the adjustments were based on the assessment rubric used for the whole students. In essence, the application of grammatical items into writing tasks and adjustments of the tasks were examples of how personalized learning implemented for the student with an autism spectrum disorder. 

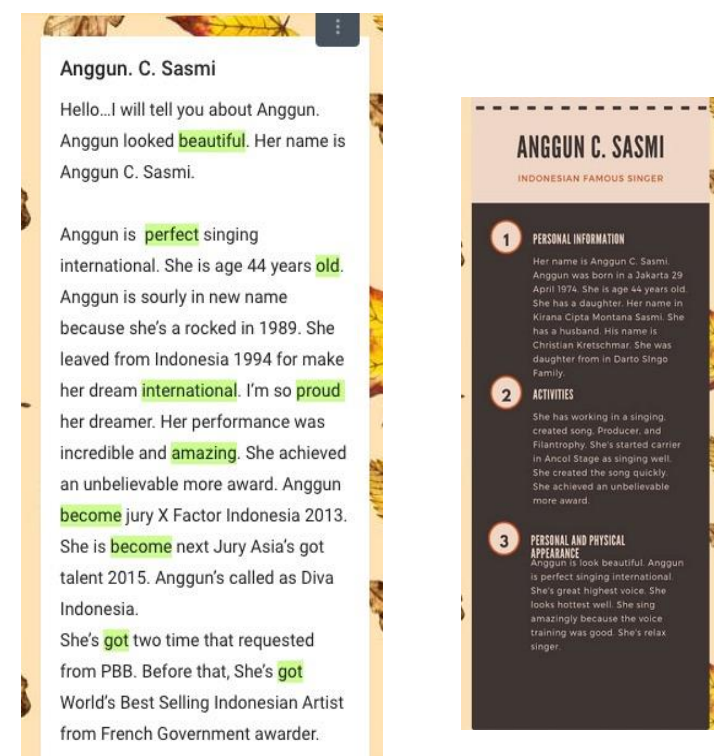

Figure 3. Writing assignments

\section{Project-Based Assignment: Blog}

The last innovation applied for the student with autism spectrum disorder was a project-based assignment in setting up a personal blog to showcase their writing works. This project-based assignment served as a practice for the student with autism spectrum disorder to tailor his learning by deciding his own choice in what website he would use to set up the blog and how he would do that. This innovation is a good practice in enabling student's voice and choice in what, when, where, and how they learn (Worthen, 2016). In this projectbased assignment, the student with autism spectrum disorder decided to use Padlet as a tool to showcase his writing works. Being asked the reasons, he explained that he felt more comfortable with this tool as he had used it last semester, and he found out that Padlet did not require complex steps to generating the blog. By tailoring the learning based on his strengths, weaknesses, and interests,
Nyawiji managed to use and generate his own Padlet to showcase all his writing assignments during his study in the Basic Grammar course. Figure 4 shows his collection of writings during one semester in this course.

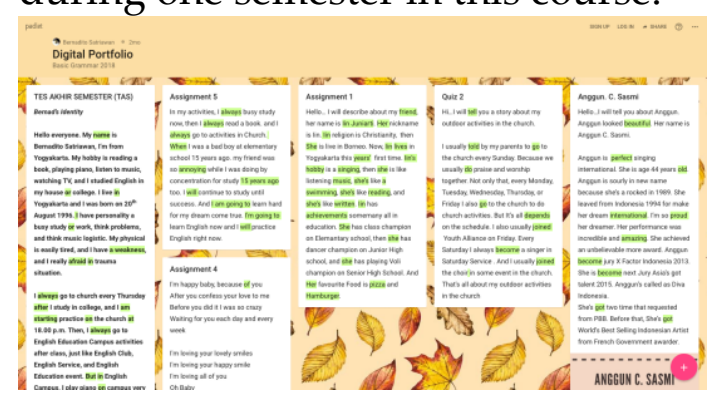

Figure 4. Digital Portfolio with Padlet

\section{CONCLUSION}

This study of how personalized learning was applied in Basic Grammar course to empower and facilitate learning and to provide ownership of learning of a student with an autism spectrum disorder in an inclusive educational setting. The implementation of personalized learning has more advantages than its challenges. In an inclusive classroom, personalized learning increases the engagement of students with an autism spectrum disorder, builds their confidence and decision-making skill, reduces the stigma of being singled out, helps them follow the classroom instructions, and reduces the level of anxiety of the students with an autism spectrum disorder. Nonetheless, its implementation has some challenges, such as the learning environment should be informed, educated, and empowered about the nature of personalized learning practices and the assessments of the personalized tasks should be aligned with both the curriculum and personalized 
learning. The process of informing, educating, and empowering peers, other teachers, and administrators was a long journey because each person has a different acceptance towards the view. Also, assessments should be adjusted based on the student's performance and progress.

To conclude, the application of personalized learning can be varied and modified based on the characteristics and needs of students with an autism spectrum disorder. Moreover, educators and teachers are suggested to implement this approach in an inclusive classroom setting to empower learning, provide opportunities for students with an autism spectrum disorder to take ownership of learning and to promote equity in education. Further studies can investigate the experience of students with an autism spectrum disorder in the personalized learning environment. A study on the perceptions and beliefs of personalized learning on students with an autism spectrum disorder might be conducted.

\section{ACKNOWLEDGEMENT}

This study was funded by Ristekdikti under Hibah Inovasi Pembelajaran Pendidikan Khusus. The results of the study have been presented in the $7^{\text {th }}$ OpenTESOL International Conference held by Ho Chi Minh Open University Vietnam in 2019.

\section{REFERENCES}

CCSSO. (2017). Equity and personalized learning: A research review. Washington, D. C.: The Council of Chief State School Officers (CCSSO). Retrieved from https://creativecommons.org/lice nses/by/4.0/.

Childress, S., \& Benson, S. (2014). Personalized learning for every student every day. Phi Delta Kappan, 95(8), 33-38.

Conroy, M. A., Stichter, J. P., \& Gage, N. (2011). Current issues and trends in the education of children and youth with autism spectrum disorders. In Handbook of special education (pp. 277-290). New York, NY: Routledge.

DENI (2016). Autistic spectrum disorder: A guide to classroom practice. The Education and Training Inspectorate (ETI) of the Department of Education in Northern Ireland (DENI). Retrieved from https://dera.ioe.ac.uk/6708/7/asd_ classroom_practice_Redacted.pdf Djoub, Z. (2018). Performance-based assessment: A shift towards an assessment for learning culture. In Hidri, S. (Ed.). Revisiting the Assessment of Second Language Abilities: From Theory to Practice. Springer.

Friend, M., \& Bursuck, W. D. (2012). Including students with special needs. Boston, MA, USA: Allyn \& Bacon.

Honda, H., Shimizu, Y., Imai, M., \& Nitto, Y. (2005). Cumulative incidence of childhood autism: a total population study of better 
accuracy and precision. Developmental medicine and child neurology, 47(1), 10-18.

Jenkins, J. M., \& Keefe, J. W. (2002). A Special Section on Personalized Instruction Two Schools: Two Approaches to Personalized Learning. Phi Delta Kappan, 83(6), 449-456.

Jones, L. E., \& Casey, M.C. (2015). Personalized learning: Policy $\mathcal{E}$ practice recommendations for meeting the needs of students with disabilities. National Center for Learning Disabilities. Retrieved from http://www.ncld.org/wpcontent/uploads/2016/04/Personal ized-Learning.WebReady.pdf.

Kim, C. (2012). The role of affective and motivational factors in designing personalized learning environments. Educational Technology Research and Development, 60(4), 563-584.

NCLD. (n.d.). Personalized learning: Meeting the needs of students with disabilities. Retrieved from https://ncld.org/personalizedlear ning.

Pane, J. F., Steiner, E. D., Baird, M. D., \& Hamilton, L. S. (2015). Continued Progress: Promising
Evidence on Personalized Learning. Santa Monica, CA: RAND Corporation.

Pritchard, A. (2009). Ways of learning. Learning theories and learning styles in the classroom. New York, NY: Routledge.

Septia, D., Mauliani, L., \& Anisa, A. (2016). Pengaruh Perilaku Anak Berkebutuhan Khusus terhadap Desain Fasilitas Pendidikan Studi Kasus: Bangunan Pendidikan Anak Autis. Prosiding Semnastek.

Setyoputri, H. A. (n.d). Handbook of inclusive education in Indonesia. One step ahead to commence an inclusive education system in Indonesia. Unpublished paper.

Sun, X., \& Allison, C. (2010). A review of the prevalence of autism spectrum disorder in Asia. Research in Autism Spectrum Disorders, 4(2), 156-167.

Weiwu, L., Li, L., \& Chen, R. (2000). Epidemiological investigation on autistic disorder in Fujian Province. Shanghai Arch Psychiatry, 12(1), 3-5.

Worthen, M. (2016). The future of personalized learning for students with disabilities. State Education Standard, 16(3), 35 